\title{
College Chinese Teaching and Improvement of College Students' Humanistic Quality
}

\author{
Ping Wu \\ College of Politics and Law, Central South University of Forestry and Technology, Changsha, China \\ Email: wuping79@126.com
}

How to cite this paper: $\mathrm{Wu}, \mathrm{P}$. (2018) College Chinese Teaching and Improvement of College Students' Humanistic Quality. Creative Education, 9, 1061-1070. https://doi.org/10.4236/ce.2018.97079

Received: April 8, 2018

Accepted: June 11, 2018

Published: June 14, 2018

Copyright (C) 2018 by author and Scientific Research Publishing Inc. This work is licensed under the Creative Commons Attribution International License (CC BY 4.0).

http://creativecommons.org/licenses/by/4.0/

\begin{abstract}
According to relevant research data, humanistic quality of contemporary college students needs to be strengthened, mainly reflected in four aspects: traditional Chinese culture, language expression, aesthetic style and emotional expression. Aiming at the humanistic accomplishment of college students, this paper discusses the effective methods of improving college students' humanistic quality in College Chinese teaching. The first one is reorganizing the content of teaching materials and enriching the content of the lecture. The second one is enriching the teaching content and extending cultural knowledge beyond the textbook. The third one is making teaching method active and combining self-study with lecture. The forth one is cultivating aesthetic style in works and developing emotional expression habits in interaction.
\end{abstract}

\section{Keywords}

College Chinese, College Student, Humanistic Quality, Current Situation, Effective Methods

\section{Introduction}

Humanistic quality refers to the comprehensive quality or the degree of development that people achieve in the humanities, which is an important part of college students' cultural quality. Humanistic quality education can be expressed as: Through the educational process such as knowledge imparting and environmental edification, human outstanding cultural achievements is internalized into human personality, temperament and accomplishment, becoming the relatively stable internal quality of human beings. Humanistic quality education of college students can be carried out in the education of Humanities and social sciences such as literature, history, philosophy and art.

For college students, the improvement of humanistic quality comes from two 
aspects: one is self-study through reading, the other is classroom teaching. The former often relies on the latter to guide them. The current situation of college students' reading is not optimistic. According to the relevant survey data, $36 \%$ have no plan for reading, while $89.7 \%$ call for effective guidance in extracurricular reading (Shi, 2012).

Therefore, opening the humanistic quality courses of college Chinese is the most direct and effective way to improve the humanistic quality of college students. This paper will analyze and summarize the present situation of College Students' humanistic quality, and discuss the effective methods to improve the humanistic quality of college students in College Chinese teaching.

\section{Current Situation of College Students' Humanistic Quality}

The content of humanistic quality education is embodied in three aspects: the reserve of humanistic knowledge, the internalization of humanistic spirit and the formation of behavior habit. As a full-time college teacher with 10 years of experience in Teaching Humanities, I know that in all aspects, the humanistic quality education of contemporary college students needs to be strengthened.

1) Traditional Chinese culture needs to be enriched

The content of Traditional culture studies is very rich. Ji Xianlin, a national master, points out, today's Sinology, which we want to revitalize, is no longer the pronoun or copy of respecting the Confucius and reading the classics, but a complete picture of the history of the Chinese nation. It really inherits and carries forward the traditional academic culture created by all the peoples living on the land of China. The role of Chinese culture is also very powerful. Traditional culture is the foundation of the country's development and growth. Learning the knowledge of Chinese culture, studying the essence of Chinese culture and promoting the spirit of it are the necessary conditions for the country's long-term development. The college students should become the backbone in the inheritance and development of the traditional civilization.

However, in the past ten years, the relevant survey data have reflected the lack of contemporary college students' Chinese culture knowledge. In 2006 the results of traditional culture survey in one university of Shanghai show that: "The quality of the traditional culture of college students is generally inadequate." In the investigation of the basic knowledge of ancient literature, nearly $30 \%$ of the students chose the wrong answer, $73.73 \%$ of students admitted that they had not read traditional literary classics for more than half a year. The proportion of students who correctly answer the date of traditional festival and the western festival is only about $50 \%$ (Li, Liu, Chen, Huang, \& Wang, 2006). The results of the survey on the cognitive level of traditional culture among the freshmen of one university of Beijing in 2016 show that: "Students' mastery of the basic common sense of traditional culture is not high on the whole." Only 8 of the 20 common cultural questions were correct at more than $60 \%$. About $21 \%$ of the students have read all four masterpieces. The rest or read 3 (about 27\%), 2 
(about 20\%), 1 (about 24\%), and even none of the masterpieces (about 8\%) (Chu, 2016).

It can be seen that in the last ten years, the amount of traditional Chinese knowledge of contemporary college students has not increased significantly. To change the current situation, we must have the effective guidance of the school and the students' conscious reading.

2) The ability to speak and write needs to be improved and the consciousness of writing norms needs to be enhanced

Language and writing ability refers to the ability to communicate and express one's own opinions through language and writing. This is a major component and an important manifestation of the humanistic quality of college students. People's internal knowledge conservation will be externalized into corresponding language and writing skills. The ability of speaking and writing couldn't be good without enough knowledge reserve. The expressing ability would be imperfect with abundant knowledge but little proper imitation and practice.

According to the results of the survey on the language quality of college students in two colleges and universities, three colleges and universities, conducted by Yan Yaping of Fudan University in 2016, In terms of oral expression, the Proportion of students which can make short speeches in front of the public and be able to express clearly and fluency respectively is $31.3 \%$ (key university), $27 \%$ (ordinary university), 26.6\% (independent college) and 10\% (community college). Proportion of students who are able to handle languages flexibly according to what happens in communication is $31.2 \%, 30 \%, 29.2 \%, 12.8 \%$. In terms of written expression, according to the analysis of the articles written by the students, it is concluded that the proportion of students in writing can be expressed clearly and fluently respectively is $22.9 \%, 20.6 \%, 19 \%, 17.9 \%$ (Yan, 2016).

According to the analysis of students' articles in one university of Beijing, 76\% of the students think that "the ability to express language is generally or not strong". More than $60 \%$ of students have experienced embarrassing or unpleasant situations caused by poor language expression. More than $10 \%$ of the students say they often meet this situation. Only $6 \%$ of the students said "write the manuscript regularly". Over half students think they aren't good at writing communication skills. "One often feels lost for words and finds lots of deficiency in writing" (Yao, Guo, Lv, \& An, 2017).

For college students, the most expressive ability of language is interpersonal communication, course paper writing and graduation thesis writing. The above cited data is not comprehensive, but it is enough to show that the two cases are not optimistic.

3) Esthetic style to be improved

Esthetic style is the comprehensive performance of a person in all aspects of aesthetic taste, which can also be called aesthetic taste. Aesthetic style or aesthetic taste is gradually formed in a long-term life practice. As a product of social and cultural environment, it could be whether elegant or vulgar. Changes in the living environment and humanistic education can change a person's aesthetic 
taste and aesthetic style.

A series of research results reflect the present situation of contemporary college students' aesthetic style. In 2010 an investigation on the present situation of the Development of the Aesthetic quality of the College students in eight Universities in Nanjing shows "the aesthetic values and utilitarian tendency of vulgarization". For the art form that students like to enjoy, the film and television works account for $92.6 \%$, the modern pop songs and dances account for $70.4 \%$, the classics account for $70.4 \%$, the photographic works account for $63 \%$, the paintings account for $33.3 \%$, of the martial arts or romantic novels account for $31.5 \%$, the symphonies account for $27.8 \%, 14.8 \%$ of all kinds of operas, and classical operas or dance dramas account for $13.0 \%$. It can be seen that college students are more inclined to a new form of recreation and entertainment, and the aesthetic style is not high (Chen, 2010).

According to the analysis of the results of the investigation on the Aesthetic Culture of five College students in Jiangsu Province in 2013, the aesthetic of contemporary college students shows the characteristics of "taking popular culture as the main body" and "the mainstream of Japanese and Korean culture". In literary and art societies, 67\% are anime, photography, film, hip-hop, guitar, and manual, while calligraphy, poetry, classical music, and Drama Societies account for only $33 \% .57 \%$ of the college students ( $96 \%$ girls) chose to watch Korean TV shows, $54 \%$ of them expressed their appreciation of Japanese and Japanese aesthetic culture, and $77 \%$ of the girls chose the "fresh and lovely" from Japan (Liu, 2013).

In 2016, 11,982 college students from 100 universities in 14 big cities in three types of areas were investigated and analyzed. According to the total score of 10 points, the average score of College Students' aesthetic emotion is 5.82, and the scores of aesthetic emotion are between 3.96 and 7.06. The highest score is for natural beauty, and the lowest is for the aesthetic sense of the humanities (He, Lu, Wang, Chen, Tan, Hu, He, \& Zhu, 2016).

Findings in universities and colleges show a common problem, that is the lack of the aesthetic sense of Chinese traditional humanities. Utilitarianism and vulgarization of aesthetic values are reflected in the recreational entertainment art form in which college students tend to focus on popular culture and take Japanese and Korean cultures as mainstream.

4) Emotional expression habits to be formed

Emotional expression is "accurately and effectively display their value relations to others, so as to get effective cooperation from others, and recognize the value relationship of others in a timely, accurate and effective way by identifying other people's emotional expression, so as to better cooperate with others" (Lei, 2011). It is one of the humanistic qualities that the college students must possess.

Under the pressure of university environment, study, employment, postgraduate entrance examination, and the prospects of confusion, contemporary college students are prone to emotional burnout, which means that "people often 
show boredom, exhaustion, and indifference in front of emotions such as affection, love, and friendship. Then lack of enthusiasm for life, learning, reduced effectiveness, weakened motivation, and long-term feelings of fatigue, anxiety and other psychological states" (Dai \& Ge, 2007).

The cultivation of good emotional expression habits can help college students to express their feelings and communicate with people better to ease the mood, relieve pressure. On the contrary, it is likely to cause depression, interpersonal ability, and even be pessimistic.

In 2015, a survey of emotional burnout in three universities showed that girls were more serious than boys, cadres were more severe than ordinary students, and rural students were more serious than urban students (Dai \& Lu, 2015). It can be seen from the beginning of the first year that the emotional expression habits of college students should be intervened uninterrupted, and girls and rural students should be paid more attention.

\section{Effective Methods to Improve College Students' Humanity Quality in College Chinese Teaching}

College Chinese focuses on cultivating and improving university students' literacy in both language and literature. Good Chinese literacy is the prerequisite for any professional college students to learn and understand professional knowledge, and also the basis for all students to express their thoughts and communicate their feelings. As a public compulsory course, College Chinese teaching has a wide range of radiation, which can affect the students of each major. Through the teaching content and teaching methods, students' humanistic qualities can be improved as a whole, so as to achieve the teaching effect. In view of the current status of contemporary college students' humanities quality, the College Chinese course can improve the teaching contents and methods from the following aspects, so as to achieve the purpose of enriching the knowledge of Chinese culture, improving the ability of language and writing, cultivating the aesthetic style, and developing the habits of emotional expression.

1) Reorganize the teaching materials, and balance reading, writing, and eloquence.

The history of the writing of the textbook "College Chinese" will always contain 4 main contents that includes literary writing, applied writing, basic knowledge of language and literature, and speech and eloquence. Contents of the teaching materials separate reading, writing, and eloquence, and forms three parts that are mutually exclusive. In the actual teaching process, it is necessary to integrate the three contents. The reason for this is that there are limited hours and not enough instruction; at the same time, reading, writing, and eloquence are integrated in essence. Reading, speaking, and writing are the three major skills of Chinese. Reading is the basis for speaking and writing. Speaking and writing are two kinds of language expressions form, the organic combination of the three can achieve cultural, practical, interesting results. 
The textbook of "College Chinese" in $80 \mathrm{~s}$ has begun to be compiled in the form of appendix to the content of practical writing. At the beginning of the twenty-first Century, it began to juxtapose practical writing with literary works in the form of formal content, or at the same time pay attention to improving students' oral expression ability and continue to this day. The "College Chinese" published by Peking University press (Meiling Huang) is divided into three parts: reading appreciation, applied writing and eloquence training. To 2016, Third Edition continues this practice. The "College Chinese" (editor in chief of Li Qijun) published by the Higher Education Press in 2015 is divided into six units: poetry, prose, fiction, script, academic, and application.

It can be seen that the more comprehensive teaching materials often put the contents of reading, writing and eloquence in the arrangement of the three parts. In the actual teaching process, these three contents need to be reorganized to integrate. There are two reasons: firstly, class hours are limited. The general situation of College Chinese courses is that they only have one semester, 2 credits, 32 classes, and the limited class hours are divided into three stages. Secondly, reading, writing and eloquence are a whole. Reading, speaking and writing are the three skills of Chinese. Reading is the basis of writing. Speaking and writing are two forms of language expression, and there is a necessary connection between them. In class, the organic combination of the three can achieve cultural, practical, and interesting effects.

For example, reading appreciation of Li Si's “Jian Zhu Ke Shu (谏逐客书)” can be compared to document writing. By virtue of this article, Li Si let the King of Qin take back the order of expelling guests. As an example of the ancient document, it fully embodies the actual effect of the official document and corresponds to the opinions in the modern public documents. "Ru Guan Gao Yu (入关告谕)" was an important announcement to stabilize the people's hearts after Liu Bang's occupation of Xianyang. Zhu Geliang's “Chu Shi Biao (出师表)” expressed the author's loyalty and filial piety, being close to the report in the modern document. By commenting on the above ancient literature, we can compare it with modern documents, analyze the similarities and differences between the two, and try to rewrite them, so as to deepen our impression and enhance the interest of official document teaching.

Liang Qichao's “learning and being a man (为学与做人)” is a typical speech. It uses a lot of calls and questions, its language is vulgar and graphic, and its structure is rigorous. It can be used as a model for speeches and speeches. Good speech as well as Churchill's "we will fight to the end", Martin Ruud Kim "I have a dream" and so on, all can be selected as the object of reading; The appreciation and recitation of poems of ancient and modern times can be carried out at the same time, Ai Qing's "snow falls on the land of China" contains rich emotion and artistic conception, repeated chanting on the sentence, which can be used as the model of recitation practice.

2) Enrich the teaching content and extend the knowledge beyond textbooks 
and classrooms

There are a limited number of subject in a textbooks and the culture of Chinese culture is extremely rich. Therefore, through the guidance and expansion of the classroom, the specific literary content can be used as an extension of knowledge within the scope of Chinese culture, and the reading appreciation of the literary selection can be upgraded into a humanistic literacy curriculum.

For example, the love poems in “Shi Jing (诗经)" can be extended in two directions. One is the love poetry, and it involves the development of Chinese Love Poems, such as the frankness of the pre-Qin period, the deep love of Wei and Jin dynasties and the euphemism of Tang and Song. Besides, it also involves appreciation of classical love poems and life story and love story of love poets, such as Yuefu poem “Shang Ye (上邪)”, Li Zhiyi’s “Bu Cao Zuo Shu (卜操作数)” Liu Yong's “Feng Qi Wu (凤栖梧)”. The other one is The Book of Songs, which involves the origin and development of poetry, and the origin and formation of The Book of Songs, the Connotation of the Six Meanings of the Book of Songs and the Tradition of the Ancient Poetry. Another is "Shi Jing (诗经)", it involves the origin and development of poetry, origin and formation of "Shi Jing (诗经)", the ancient poetry tradition, and so on.

The related contents of "Liang Shiqiu's prose" are more suitable for the extension. Liang Shiqiu was deeply influenced by the traditional culture, and unique in modern literati. Although long in troubled times, and relocating several times, but he still maintain an elegant scholar demeanor, prose style is simple, meaningful and cultural. This kind of work needs careful reading, and the expansion of human knowledge can be done with the text. Many places have to be explained to understand the author's easy-to-attack mindset attitude, artistic way of life, open-minded attitude towards life, and ancient Chinese culture has been included.

3) Make teaching methods active, combining self-learning with lecturing.

It is a worthy issue to use limited hours and develop unlimited possibilities in class. Combining self-learning with lecturing, changing the status of the teacher's lecture hall, making teaching methods active and inviting students to join in the class, which can effectively extend the learning time and expand the learning space.

There is an open-ended question between the class and the lesson, leaving room for every student to think and express. It can be a question for this class, or a preview for next class. It can be a small problem completed by a single person or a complex problem that can be completed by many people. Before class, if you want to have wonderful comments and expressions, you have to work hard after class to improve your reading and language skills.

For example, when learnt “The Song of Everlasting Regret (长恨歌)" of Bai Juyi, we can ask "What do you know about Bai Juyi?" before class and "What do you think about the love theme of "The Song of Everlasting Regret" after class. Problems should be fully open, humanistic and ideological. Bai Juyi's life is 
available on the internet, but deep insights come from in-depth reading and research, such as Bai Juyi's past life, his son, marriage, friendship, Bai Juyi's scientific experience, Bai Juyi's outlook on life, and Bai Juyi's influence on literary poetry creation, which can be the subject of study and discussion. On the love theme of "The Song of Everlasting Regret" view has always been different, the subject of this book can be the object of the discussion, and it can also be used to explain student's own view of love.

Divide some of the teaching content to students and provide students with the space to make full use of it. The stylized teaching method is often used in practical writing. First of all, it talks about standardized formats, and then makes exercises, and then there are comments for revision. The standard format is mostly instilled by the teachers, the classroom is less interesting, the students' learning enthusiasm and attention are difficult to maintain for a long time, and the learning effect is difficult to guarantee. Students can also be required to make courseware and give lectures by themselves. If the rostrum is given to the student, it will improve the learning efficiency, the learning ability and the expression of language. For example, there are 15 types of document writing, but the format of the text is the same, the text is similar, the key to the lecture is the proficiency of the writing. They can devote themselves in choosing from examples and writing samples and correcting errors. The standardization process will enable students to develop their writing skills and obtain deep impression.

4) Cultivate the aesthetic style with real writings and develop the habit of expressing emotions in interaction

The creation of literary works is an artistic symbol of life and feelings. It has many aesthetic features such as imagery, emotion and sense of music. The vivid and beautiful verses can always arouse the reader's feelings of beauty. Through the analysis of the language of the work, the teacher leads the students to feel the beauty of image, emotion, artistic conception and music. Therefore the teaching of literary works has a strong aesthetic function, which makes students cultivate their aesthetic style by appreciating literary works.

The beauty of the music, emotion and artistic conception can be felt through the appreciation of ancient poetry. For example, When reading Quyuan's "Guo Shang (国歾)", people can feel the beauty of balance, neatness, rise and fall, and the tortuousness of language. The deep emotion and the fiery beauty can also be felt. Balanced beauty is formed by antithesis and parallelism. The tortuous beauty is formed by rhymes and repetition. The beauty of equilibrium is formed by antithesis and parallelism. The tortuous beauty is formed by rhyme and repetition.

The beauty of the image, picture and emotion can be felt through the appreciation of novel. Xiao Hong's “ The History of Hulan River (呼兰河传)” is good at using children's perspective and fresh language to express characters and environmental picture, has its own unique aesthetic characteristics. As Ge Haowen said, Xiao Hong's language is "The graceful and concise of the registered trade- 
mark", which is very interesting. In the tragedy of a special age Lu Yao's "ordinary world (平凡的世界)"shows the best of human emotions, nostalgia, love, affection, friendship. Life is poor and difficult, but between the lines there always the sunlight, strong emotions and deep feelings, so life is full of hope.

For the students with slack emotion, we can train them in the class with interaction. Increase the chance of emotional communication with the help of topic discussion and work review. We can also express directly through the recitation of poems and proses and the analysis of the characters. Such as Zhu Ziqing's "A view of my father's back" describes the farewell between the father and the son at the bus station, it is the truth of truth story. Reading such kind of works can be a long-awaited family affection, motivating the desire of family sentiment. Dai Wangshu's "Rain Alley (雨巷)" contains a graceful charm and elegant style of Chinese classical poetry. In the poem "girl" is considered to be a poet's long-awaited beautiful and melancholy girl. Read this poetry aloud with expression let people immersed, feeling and expressing the poet's feelings. Read this kind of work is a great emotional expression in practice. Zhu Ziqing's "back view (背影)” depicts the scene of father and son's farewell in Pukou station, and writes real feelings with real things. Reading of such works may be a long experience of family experience, stimulating the desire of expressing affection in the heart.

\section{Conclusion}

To sum up, the course "College Chinese" can make up for the shortage of professional education, improve the humanistic quality of college students, and also enrich the knowledge of Chinese culture, improve the ability of language and characters of expression and aesthetic style, and also improve the cultivation of emotional expression. The main methods are as follows: reorganizing the content of teaching materials and enriching the content of the lecture; enriching the teaching content and extending cultural knowledge beyond the textbook; making teaching method active and combining self-study with lecture; cultivating aesthetic style in works and developing emotional expression habits in interaction.

\section{Fund Project}

This paper is financed by the project of 12th Five-Year Plan of Education Science in Hunan Province: "Judging the Cultivation of Humanistic Quality of Today's College Students from the Campus Festival Slogans” (XJK014BGD092).

\section{References}

Chen, Z. Z. (2010). The Status Quo of College Students' Aesthetic Development: Problems and Solutions. Journal of Yangzhou University (Higher Education Study Edition), 6, 62-65.

Chu, J. B. (2016). Investigation of the Cognition of Freshmen's Traditional Culture: A 
Case Study of Grade 2015 Freshmen in Beijing Institute of Petrochemical Technology. China Market, 8, 106-109.

Dai, L., \& Ge, M. G. (2007). Types and Educational Countermeasures of College students' emotional Burnout. Chinese Journal of School Doctor, 8, 453-454.

Dai, L., \& Lu, Y. (2015). A study on College students' emotional Burnout. Journal of Anhui University of Technology (Social Sciences), 9, 138-139.

He, W., Lu J. M., Wang, H. Y., Chen, N. Q., Tan Z.Z., Hu, C. Y. He, B. Q., \& Zhu, C. Z. (2016). An Investigation of Contemporary College Students' Aesthetic Affection in China. Journal of Psychological Science, 11, 1318-1325.

Lei, J. D. (2011). Research on Social Construction of College Students on the Basis of Emotional Expression (p. 3). Master Thesis, Chongqing: Southwest University.

Li, J. Q., Liu, H. Y. Chen, P., Huang, H. Y., \& Wang, X. L. (2006). The Investigation of Sinology. Journal of Social Sciences, 6, 1-4.

Liu, L. L. (2013). Investigation and Analysis of Contemporary College Students' Aesthetic Culture and Countermeasures-Taking College Students in Jiangsu as an Example. Beauty and Times (the Last Ten-Day Period of a Month), 8, 38-40.

Shi, D. (2012). Survey and Analysis of the Reading Status of University Students-Thoughts on the Relationship between Reading Status of University Students and the Domestic Publishing Industry. Journal of Library and Information Sciences in Agriculture, 1, 142-145.

Yan, Y. P. (2016). The Investigation and Countermeasure Research on Contemporary College Students' Language Quality. Modern Education Science, 3, 98-104.

Yao, X., Guo, J., Lv, S. H., \& An, H. J. (2017). The Study on the Present Situation and Countermeasures of Language and Character Expression Ability of College Students of Science and Engineering Universities. Ability and Wisdom, 2, 17. 